\title{
INCORPORANDO A TERRITORIALIDADE EM UM PROGRAMA DE EDUCAÇÃO AMBIENTAL BIORREGIONALISTA: O CASO DO PROJETO "MORADA DOS SABERES", SÃO MATEUS DO SUL (PR)
}

\author{
Manuela Dreyer da Silva ${ }^{1}$ \\ Karin Cristina Escobar Yamashiro ${ }^{2}$ \\ Décio Estevão do Nascimento ${ }^{3}$
}

Resumo: $O$ objetivo deste artigo foi apresentar os resultados do projeto "Morada dos Saberes" à partir do diálogo com elementos da territorialidade, evidenciando as contribuições e os desafios para a prática de educação ambiental no município de São Mateus do Sul. O projeto foi pensado como multiplicador, tendo como método de base o biorregionalismo. Foram feitas oficinas para educadores, elaboração de materiais paradidáticos, promoção de espaços de debate sobre temáticas socioambientais locais, além do fortalecimento de parcerias da rede educativa. A territorialidade, permeando as distintas ações pensadas para o projeto, mostrou-se efetiva como conceito chave no desenvolvimento de projetos em educação ambiental.

Palavras-chave: Biorregionalismo; Territorialidade; Saberes Locais. 


\section{Introdução}

A territorialidade tem sido foco de estudos e discussões em diversas áreas (HAESBAERT, 2004, p.03; LAGES et al., 2004, p.08), sendo também levantada sua importância para área da educação (LOUREIRO, 2008, p.242; 2003, p.48.). Para Little (2002, p.253), a territorialidade considera a conduta territorial como parte dos humanos. O autor define territorialidade como "o esforço coletivo de um grupo social para ocupar, usar, controlar e se identificar com uma parcela específica de seu ambiente biofísico" (LITTLE, 2002, p.253). Outro aspecto fundamental exposto por Little (2002), relevante para o presente artigo, é que a territorialidade tem uma multiplicidade de expressões (LITTLE, 2002, p.260).

Enquanto processo de conexão do natural e do humano, a territorialidade se mostra, portanto, fundamental para a ação educativa. Para Santos (2005, p.253), o território usado se constitui em uma categoria essencial para a elaboração sobre o futuro, em um processo complexo e dinâmico. E se a educação pode ser considerada como promotora de transformações sociais (JACOBI, 2003, p.196; 2005, p.233), há então uma importante conexão dessas temáticas, não apenas no campo teórico, mas também em sua práxis.

O propósito deste artigo não é o de discutir os endereçamentos da territorialidade ou mesmo da educação ambiental, como bem apresentou e discutiu Carvalho (2004, p.16). O intuito é demonstrar um estudo de caso que nasce de uma práxis educativa e vem permeada de reflexões sobre as práticas sociais territoriais: o projeto de educação ambiental "Morada dos saberes: repensando educação, ambiente e sociedade". Criado para implementar um espaço socioambiental sobre discussão territorial no município de São Mateus do Sul, o projeto atuou como um centro de mobilização comunitária e formação ambiental.

Um dos pressupostos da Educação Ambiental (EA) é exatamente o de trabalhar os problemas específicos de um dado grupo social (JACOBI, 2003, p.204). E é nesse viés que se manifesta um importante papel da EA almejado pelo projeto citado: ter uma função transformadora (LOUREIRO, 2003, p.49), na qual a corresponsabilização dos indivíduos é necessária para se buscar respostas para problemáticas socioambientais.

Uma das vertentes da EA que considera essa complexidade territorial é a vertente biorregionalista, a qual parte da ideia de resgatar uma conexão intrínseca entre comunidades humanas e o ambiente, a partir da valorização da realidade e características de um dado local (SATO; SANTOS, 2003, p.274). Uma biorregião reúne não apenas aspectos geográficos, como também a história e a cultura que transformam um território, havendo um sentimento de "lugar de vida" relacionado ao meio (SAUVÉ, 2005, p.28).

O biorregionalismo foca no desenvolvimento social e ambiental como meio de vida (SATO; SANTOS, 2003, p.274) e está centrado num enfoque participativo e comunicativo, almejando o comprometimento dos atores sociais 
num processo de reconhecimento do meio e de identificação das problemáticas ou das perspectivas de desenvolvimento local (SAUVÉ, 2005, p.31).

A partir dessa abordagem, o projeto "Morada dos Saberes" foi estruturado para funcionar como fomentador de discussões sobre o território, na perspectiva do biorregionalismo, a partir da realização de oficinas para educadores, elaboração de materiais paradidáticos, promoção de espaços de debate sobre temáticas socioambientais locais, além do fortalecimento de parcerias da rede educativa de São Mateus do Sul.

O presente artigo visou, portanto, apresentar os resultados do projeto "Morada dos Saberes" à partir do diálogo com elementos da territorialidade, evidenciando as contribuições e os desafios para a prática de educação ambiental no município de São Mateus do Sul.

\section{Metodologia}

\section{Área de aplicação do projeto: São Mateus do Sul}

São Mateus do Sul é um município com recente maioria de sua população residente no meio urbano (ainda com grande vínculo no meio rural), e possui problemáticas socioambientais importantes, como: redução da cobertura vegetal; desordenamento no uso e ocupação do solo; conflitos de territorialidade e desconhecimento da importância da ecorregião onde se insere (Floresta Ombrófila Mista).

O município está localizado na porção sul do estado do Paraná. Servindo inicialmente como pouso de expedições militares e de viajantes, apenas após 1877 começaram a chegar à região seus primeiros moradores, emigrantes do Sul do Brasil. Logo depois, em 1885, chegaram imigrantes alemães; em 1890, os poloneses, que originaram as colônias Iguaçu, Canoas, Cachoeira, Taquaral e Água Branca; e em 1907 chegaram os ucranianos (ASSUNÇÃO, 2004, p.58). Essas diferentes culturas influenciam até os dias de hoje o cotidiano local, o modo de vida de seus habitantes e a forma com que eles se relacionam com o ambiente onde vivem, importantes características a serem consideradas pelo projeto "Morada dos Saberes".

São Mateus do Sul encontra-se sob o domínio da Floresta Ombrófila Mista ou Floresta com Araucária. No Paraná, essa formação florestal já representou cerca de $37 \%$ da área do estado, porém atualmente restam menos de $1 \%$ da cobertura original (CASTELA; BRITEZ, 2004, p.8). Até a metade do século XIX, o município era praticamente todo coberto pela Floresta com Araucária, que foi sendo transformada pela atividade agrícola, de extração madeireira e de extração de xisto. Atualmente, mesmo com muitos fragmentos florestais não originais, a floresta no município possui grande importância biológica, histórica e cultural. Segundo levantamento de Hauer (2010, p.197), 
existem no município quatro sistemas faxinais ${ }^{4}$ legalmente reconhecidos. São Mateus do Sul também possui importantes corpos hídricos - Rio Iguaçu e Rio Negro, além dos Rios da Areia, da Barra Feia, de São Miguel, Rio Claro, Potinga, Tijuco, Taquara, Água Branca, Água Suja e Três Poços.

Nesse cenário heterogêneo de importância biológica, recente urbanização, presença de grandes empreendimentos de exploração do xisto e presença de comunidades rurais e tradicionais, a territorialidade e 0 biorregionalismo permearam a estruturação do projeto "Morada dos Saberes", descrito a seguir.

\section{Proposta Educativa}

O projeto "Morada dos Saberes" foi iniciado em 2015 e teve dois anos de duração. Neste intervalo de tempo, estruturou um programa de EA utilizando como metodologia central o biorregionalismo. Diferentes frentes de atividades foram pensadas para o projeto.

Como atividade central foram realizadas oficinas de educação ambiental com educadores por se acreditar na eficiência da contínua multiplicação das discussões socioambientais na escola e nas comunidades onde eles atuam. De acordo com Teixeira e Oliveira (2008, p.06) os professores são um dos principais responsáveis na construção de saberes dos estudantes em diferentes aspectos, incluindo as informações sobre temáticas ambientais. No início das atividades, foram selecionados 56 educadores da rede municipal e estadual de ensino, por meio da parceria desenvolvida com a Secretaria Municipal de Educação e o Colégio São Mateus. As oficinas de formação ocorreram entre os meses de outubro de 2015 até fevereiro de 2017, totalizando 13 intervenções coletivas. Foram debatidos temas locais, incluindo a participação de instituições e profissionais convidados, tanto do município como de outras regiões do Estado do Paraná. As temáticas foram definidas ao longo do andamento das oficinas, considerando aspectos relacionados aos Municípios Educadores Sustentáveis, metodologia trabalhada pelo Ministério do Meio Ambiente (BRASIL, 2005), e considerando a demanda e sugestões dos parceiros e do público envolvido (construção participativa) e das características regionais.

Paralelo a esse trabalho, os educadores foram orientados a desenvolver um projeto multiplicador em suas escolas e comunidades (denominado de projeto paralelo), com a temática escolhida por eles. Os educadores também foram envolvidos no trabalho de coleta de lendas locais, as quais embasaram a construção de materiais paradidáticos (abaixo descritos).

\footnotetext{
4 Faxinal é definido no Decreto no 3446 de 14/08/1997 como um sistema de produção camponês tradicional, característico da região Centro-Sul do Paraná. Tem como traço marcante o uso coletivo da terra para produção animal e a conservação ambiental, integrando: a produção animal coletiva; a produção agrícola, de subsistência para consumo e comercialização; e o extrativismo florestal de baixo impacto, como o manejo de erva-mate, araucária e outras espécies nativas.
}

revista brasileira educação ambiental 
Também ocorreram debates e oficinas direcionados a estudantes do Curso Técnico em Meio Ambiente, do Colégio São Mateus. Os encontros seguiram a temática central de "multiterritorialidade em São Mateus do Sul". Alguns destes estudantes receberam treinamento aprofundado sobre a Floresta com Araucária e contação de histórias, estendendo seus trabalhos às escolas municipais rurais.

Como um dos diferencias do espaço educativo criado, o projeto construiu um diorama, com o objetivo de receber diferentes públicos para discussões de características da fauna e flora da região. Diorama é uma forma de representação de uma cena da vida real, muito utilizado em museus para representar cenários, servindo para contextualização de fatos de diversos temas (ASENSIO; POL, 1996, p.12). Nos museus de história natural, são usados para expor relações entre organismos e ambientes, funcionando de forma importante na sensibilização e percepção (ASH, 2004, p.84). No caso do "Morada dos Saberes", a composição foi feita com elementos que representam a Floresta com Araucária.

O projeto também elaborou materiais educativos como referência em temáticas socioambientais para multiplicação e replicação do biorregionalismo. Foram confeccionadas 9 apostilas incluindo as temáticas discutidas durante as oficinas, com a participação de diferentes atores sociais de São Mateus do Sul, além da organização de um livro sobre os distintos saberes do município.

Em relação ao fortalecimento da rede educativa municipal, foram trabalhadas competências relacionais para construção de ações coletivas envolvendo diferentes atores sociais (como debates, intervenções nas escolas e reuniões entre parceiros).

\section{Resultados e Discussão}

Em dois anos de existência, o Morada dos Saberes mobilizou 94 participantes diretos (entre educadores da rede municipal e estadual de ensino e estudantes do Curso Técnico de Meio Ambiente do Colégio São Mateus) sendo que o número de participantes eventuais foi de 1077 (participantes de debates, palestras e visitas à exposição).

O Quadro 1 sintetiza os resultados alcançados pelo projeto com os distintos públicos trabalhados. Os temas trabalhados nas oficinas de formação foram: (1) EA Biorregionalista e Municípios Educadores Sustentáveis; (2) Elaboração de projetos; (3) Histórico da Floresta com Araucária; (4) Que projeto nós queremos para nossa escola; (5) Erva-mate e suas potencialidades: trabalhando a territorialidade; (6) Ações práticas nas escolas; (7) Ambientes sustentáveis nas escolas; (8) Elaborando nosso Projeto Político Pedagógico (PPP); (9) Problemáticas socioambientais; (10) Discutindo PPP potencialidades do território; (11) Ações sociais praticadas em nosso município; (12) Monitoramento e avaliação de projetos paralelos de EA; (13) Estratégias metodológicas e o processo de ensino-aprendizagem. Estes mesmos temas 
foram registrados em apostilas desenvolvidas em parceria com diferentes profissionais.

Quadro 1: Atividades ofertadas pelo projeto, entre 2015 e 2017.

\begin{tabular}{|c|c|}
\hline Público Direcionado & Atividades \\
\hline $\begin{array}{l}\text { Professores da rede } \\
\text { municipal/estadual }\end{array}$ & $\begin{array}{l}\text { Capacitação de } 56 \text { educadores por meio de oficinas de } \\
\text { educação ambiental biorregionalista e desenvolvimento de } \\
\text { projetos multiplicadores }\end{array}$ \\
\hline $\begin{array}{l}\text { Estudantes do curso Técnico } \\
\text { em Meio Ambiente do Colégio } \\
\text { Estadual São Mateus }\end{array}$ & $\begin{array}{l}\text { Capacitação de } 40 \text { estudantes por meio do programa de } \\
\text { orientação para construção de ações voltadas ao } \\
\text { (re)conhecimento do território de São Mateus do Sul, por } \\
\text { meio de atividades integradas ao currículo escolar }\end{array}$ \\
\hline Público diverso & $\begin{array}{l}\text { A exposição (diorama) "A Fauna dos Pinheirais" recebeu } \\
\text { mais de } 600 \text { visitantes e seu maior objetivo foi levar ao } \\
\text { público novas sensações e (re)conhecimento do território, } \\
\text { demonstrando as relações delicadas entre os seres } \\
\text { humanos, os animais e o ambiente }\end{array}$ \\
\hline $\begin{array}{l}\text { Profissionais da educação da } \\
\text { rede municipal de ensino }\end{array}$ & $\begin{array}{l}\text { Participação na Semana Pedagógica de São Mateus do Sul } \\
\text { (2016), com a exposição da temática: fragilidades e } \\
\text { potencialidades da ação escolar para a transformação } \\
\text { social. O evento reuniu mais de } 170 \text { profissionais da } \\
\text { educação e contou com a parceria da UFPR }\end{array}$ \\
\hline Público diverso & $\begin{array}{l}\text { Promoção de debates e palestras com a participação de } \\
\text { mais de } 200 \text { pessoas. } \\
\text { Temáticas diversas: Erva-mate e identificação geográfica; } \\
\text { Comunicação Comunitária; Floresta com Araucária e sua } \\
\text { história em São Mateus do Sul; Fauna paranaense }\end{array}$ \\
\hline Público diverso & $\begin{array}{l}\text { "Cine Morada": exibição de filmes com temáticas } \\
\text { socioculturais e ambientais com roda de conversa e troca de } \\
\text { experiências }\end{array}$ \\
\hline $\begin{array}{l}\text { Estudantes do ensino } \\
\text { fundamental das escolas do } \\
\text { campo de São Mateus do Sul }\end{array}$ & $\begin{array}{l}\text { Participação na Semana Municipal de Meio Ambiente (2016) } \\
\text { com atividades para } 500 \text { estudantes das escolas do campo, } \\
\text { com a proposta de instigar a reflexão sobre a relação entre } \\
\text { seres humanos e natureza (contação de histórias como } \\
\text { ferramenta) }\end{array}$ \\
\hline
\end{tabular}

Fonte: Autoria própria.

Como a proposta do projeto trazia o princípio de participação na escolha e decisão das atividades, é possível perceber uma variedade nas temáticas das oficinas, retratando a diversidade de interesse dos participantes. Segundo Lobino (2013, p.110) é habitual que ações de educação ambiental se ampliem a medida que os processos ocorram, saindo dos temas clássicos para uma abordagem de temas cada vez mais conflituosos, que traduzem representações e interesses múltiplos.

Uma das oficinas mais significativas na opinião das professoras participantes foi a oficina de elaboração de Projetos Político Pedagógicos 
(PPP). Essa oficina teve uma duração maior (de 3 encontros), nos quais os docentes relataram que acreditam na importância do instrumento, no entanto não participam da elaboração do documento em suas escolas. Apenas duas profissionais comentaram ter presenciado diretamente processos participativos de construção dos PPP em São Mateus do Sul.

Um PPP, segundo Lobino (2013, p.35) tem o potencial de redesenhar uma nova cultura nas escolas, e evidencia a importância da construção da autonomia do professor por meio de sua participação social. Os PPPs devem ser, para isso, construídos e apropriados coletivamente. Em relação à abordagem territorial, o PPP poderia ser considerado ferramenta estratégica, ao apontar a indissociabilidade das questões ambientais das sociais, além de caminhos para um maior entendimento do território e diálogo intercultural.

Como resultado dessa discussão foi, então, estruturado um Projeto Político Pedagógico para se trabalhar o biorregionalismo em São Mateus do Sul (Figura 1). O PPP Morada dos Saberes pretendeu pincelar contribuições educativas para o município, por meio de um cardápio de atividades e registro das ações realizadas ao longo do projeto. O PPP trabalhou com três eixos principais: o conceitual, o situacional e o operacional. O eixo conceitual contém a idealização, o sonho de futuro, os princípios e valores relacionados à educação ambiental, características essas trazidas durante as oficinas. $O$ eixo situacional refere-se às características presentes do contexto onde esse PPP se insere, o município e suas relações educativas. Já o eixo operacional descreve estratégias e possibilidades pensando São Mateus do Sul como um potencial Município Educador Sustentável. O material foi disponibilizado para todos os participantes e escolas e encontra-se também disponível na página virtual do projeto. $O$ intuito é estimular iniciativas educadoras em diferentes municípios, de modo que os cidadãos se envolvam e participem cada vez mais nas discussões socioambientais das regiões onde vivem.

Neto e Silva (2004, p.07) discutem a elaboração de Projetos Político Pedagógicos como mecanismo de autonomia escolar, relacionando o instrumento com a apropriação do território pela escola. Para os autores, a implementação da autonomia tem consequências na gestão das escolas e na sua integração em territórios, ao se afirmar poderes periféricos (das próprias escolas), mobilização local dos atores e contextualização da ação política.

Além das oficinas, os professores estruturaram projetos paralelos com o viés de multiplicação. Estes projetos também retrataram a diversidade de representações do público, sendo aplicados nas escolas e nas comunidades do município. Vinte e quatro escolas se envolveram neste trabalho. Corroborando essa proposta de regionalização das ações, evidencia-se o trabalho de Haesbaert (2004, p.344), que aborda e explora o conceito de identidade regional e as múltiplas dimensões do espaço. Para Kawahara e Sato (2005, p.226), atividades como essa evidenciam uma importante função da Educação Ambiental, ao dar audiência às vozes das diferentes comunidades para conhecer, não receitas, mas possibilidades de diferentes formas de se estar no mundo atual.

Revbea, São Paulo, V. 13, № 2: 214-227, 2018. 


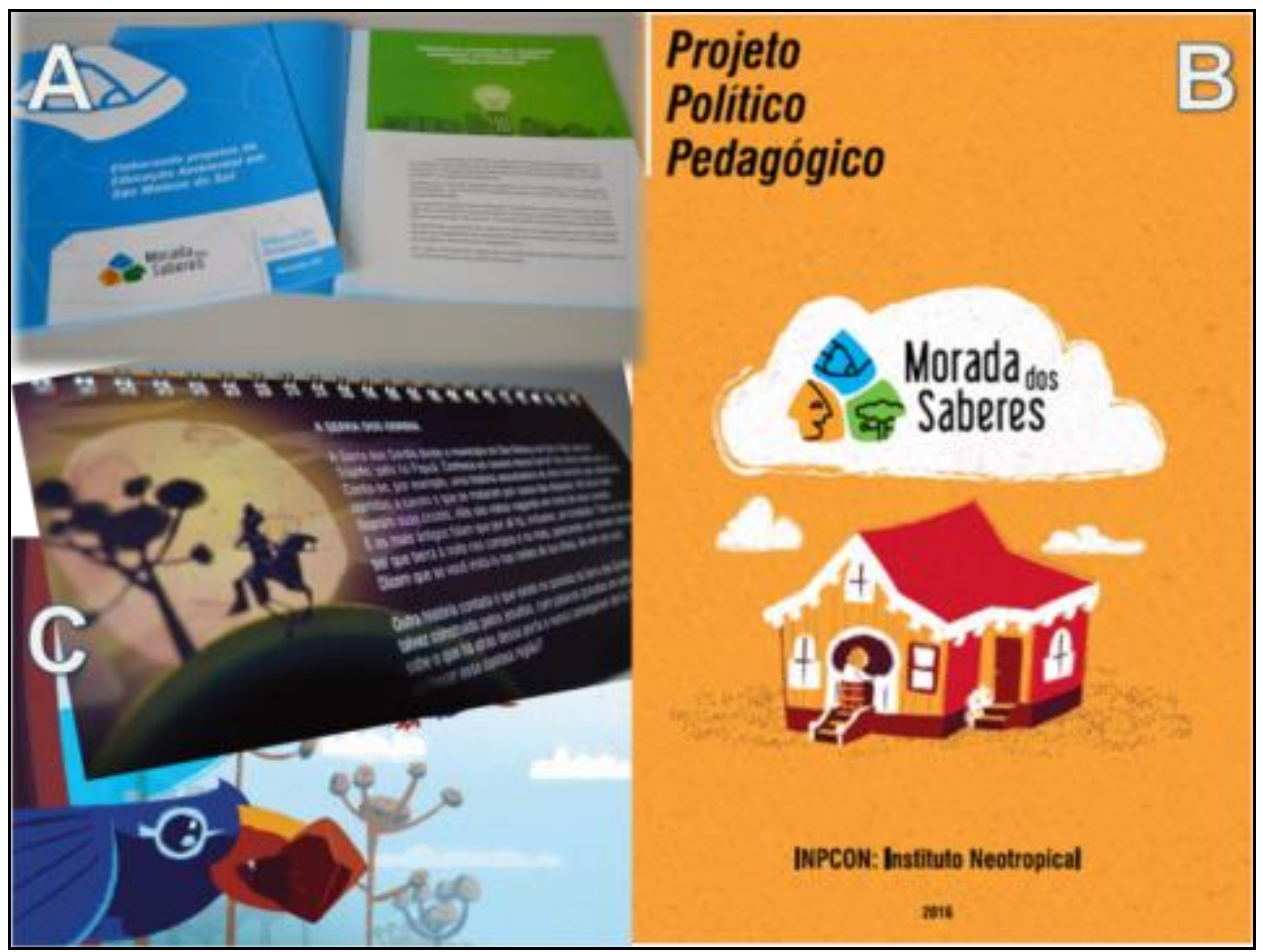

Figura 1: Materiais produzidos durante o projeto "Morada dos Saberes". A: uma das apostilas feitas para registro das temáticas trabalhadas durante as oficinas. B: Projeto Político Pedagógico Morada dos Saberes. C: Calendário de lendas coletadas em atividades nas escolas municipais de São Mateus do Sul. Fonte: acervo do projeto "Morada dos Saberes".

Ainda em relação aos materiais desenvolvidos pelo projeto, foi possível organizar uma coleção de diferentes lendas locais, as quais embasaram a produção de um importante livro paradidático, com a história da região contada por membros da comunidade, denominado "Livro dos Saberes de São Mateus do Sul" (Figura 2). O livro procurou reunir alguns saberes do município por meio de relatos importantes que retratam características ambientais, sociais e culturais, valorizando a identidade local. No livro, também foram inseridas dicas pedagógicas de como trabalhar nas escolas os diálogos entre saberes locais e os saberes técnicos sobre a Floresta com Araucária.

A experiência de construção do livro evidenciou a temática da territorialidade nas ações de educação ambiental do projeto. À medida que os relatos viravam histórias escritas e eram compartilhados entre os participantes, os diferentes símbolos (representações do território) eram reescritos, iniciando a constituição de outros mitos e de outros lugares. Estes mitos e os lugares, por sua vez, abrigaram a construção e a sedimentação dos vínculos com a natureza, como bem discutido no trabalho de Guimarães (2002, p.129). O território retratado no livro apresentou, desse modo, historicidade e, sobretudo, distintas memórias, identidades e simbolismos, características essenciais para se discutir as percepções de uma dada localidade (RISSO, 2014, p.318). As 
atividades didáticas incluídas no livro foram pensadas, então, a partir dessas distintas representações, promovendo o diálogo entre gerações e culturas.



Figura 2: Imagem do "Livro dos Saberes de São Mateus do Sul". Representação de algumas ilustrações do interior do livro. Fonte: acervo do projeto "Morada dos Saberes".

Pode-se dizer, assim, que o projeto "Morada dos Saberes", por meio de suas oficinas e desenvolvimento de materiais, colaborou com o diálogo entre conhecimento científico e o conhecimento local. Esta ponte criou vínculos entre a diversidade cultural do município e as diferentes visões de educação.

Já em relação ao diorama (Figura 3), foi possível perceber, durante o período de visitação, que o público exibia reações de surpresa, alegria e curiosidade, progredindo para sessões de perguntas sobre as espécies representadas. O público também apresentou reações de admiração e estranheza ao perceber que não conhecia muito da fauna presente no município. Considerando que é necessário conhecer as representações que os indivíduos aceitam como ambiente e que a produção desse saber deve ser validada e apropriada pelos grupos sociais (SATO; SANTOS, 2003, p.261), o presente trabalho mostrou o potencial do uso do diorama como estratégia de EA biorregionalista. 


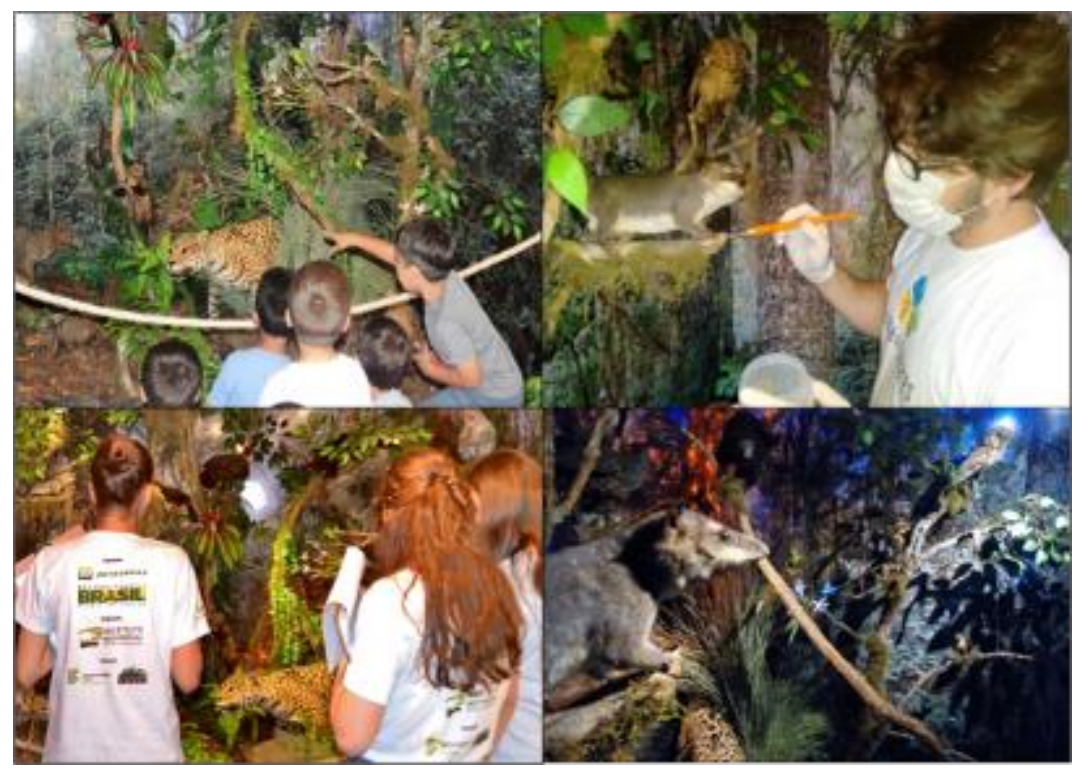

Figura 3: Representações do Diorama do projeto "Morada dos Saberes". Fonte: acervo do projeto "Morada dos Saberes".

A territorialidade, permeando as distintas ações pensadas para o projeto "Morada dos Saberes", mostrou-se efetiva como conceito chave no desenvolvimento de programas e projetos de EA. Como apontado por Loureiro (2008, p.242), discutir um território por meio da EA traz à tona a necessidade de se construir atividades que facilitem o entendimento de onde cada educador e educando se situa (comunidade, família, classe social, cultura regional, individualidade). Os resultados apontados pelo "Morada dos Saberes" mostram a potencialidade do uso das lendas locais e suas relações com o uso dos recursos naturais como tema propulsor de importantes discussões sobre a apropriação do território.

Segundo Lobino (2013, p.93) "é preciso criar um 'nós' tão amplo quanto possível em torno das escolas e envolvê-las na comunidade", o que demonstra a importância de se vincular o tema às noções de território que essas "comunidades" trazem. Compreender a maneira pela qual as identidades se projetam nos territórios cotidianos, ligadas a toda uma dinâmica socioambiental, pode ser uma forma de aliar às questões culturais e a natureza na formulação de políticas públicas locais e regionais (SANTOS et al., 2009, p. 33).

\section{Conclusões}

O desenvolvimento do projeto "Morada dos Saberes" possibilitou o compartilhamento de singularidades e experiências, evidenciando sujeitos sociais importantes para o estabelecimento de um processo educativo contextualizado e crítico em São Mateus do Sul. As atividades e os materiais produzidos por meio de processos participativos, tanto com as escolas como 
com comunidades rurais, possibilitou a discussão do sentido de territorialidade, identidade e pertencimento.

No que diz respeito ao processo de formação de multiplicadores à partir do biorregionalismo, conclui-se que a troca de informações entre os professores participantes e a troca de suas experiências nos projetos paralelos fortaleceram os canais de comunicação da rede educacional de São Mateus do Sul, culminando em uma efetiva experiência formativa, de (re)conhecimento do local e de contextualização para os sujeitos individuais e coletivos.

O projeto acredita, assim, ter contribuído no fortalecimento das parcerias que atuam na temática socioambiental local e na representação das características ambientais e socioculturais, valorizando a história e a conexão das pessoas com o ambiente em que vivem.

A utilização do biorregionalismo como ferramenta educacional se mostrou efetiva, ao modo que evidenciou a diversidade cultural local, o interesse de educandos e educadores na busca pelo seu reconhecimento e as múltiplas territorialidades de São Mateus do Sul. Dentro da perspectiva da territorialidade foi possível resgatar as histórias locais e as relações socioambientais das comunidades participantes.

É preciso reconhecer, no entanto, que diversos desafios existentes na região não foram contemplados na ação desenvolvida. A consolidação de espaços de democratização da educação, como conselhos escolares ou similares, poderiam colaborar para a resolução de desafios socioambientais locais, reconhecendo na territorialidade uma dimensão fundamental da afirmação desses direitos coletivos.

\section{Agradecimentos}

À Coordenação de Aperfeiçoamento de Pessoal de Nível Superior (CAPES) pela concessão de bolsa, ao Instituto Neotropical - Pesquisa e Conservação (INPCON) pela realização do projeto "Morada dos Saberes", à Petrobras e ao Governo Federal pelo patrocínio e ao Instituto Federal do Paraná pelo apoio na realização das ações.

\section{Referências}

ASENSIO, M.; POL, E. Siguen siendo los dioramas uma alternativa efectiva de montaje? Rev. Museologia. v.8, p.11-20, 1996.

ASH, D. How families use questions at dioramas: ideas for exhibit design. Curator. v.47, n.1, p.84-100, 2004. Disponível em: <http://onlinelibrary.wiley.com/doi/10.1111/j.2151-6952.2004.tb00367.x/pdf>.

Acesso em: 19 Maio 2017. 
ASSUNÇÃO, H.K. 2004. Parque industrial do xisto: estratégia de desenvolvimento local para São PMateus do Sul-PR. Dissertação de mestrado apresentada ao Programa de Pós-Graduação em Geografia da Universidade Federal de Santa Catarina. 150p.

BRASIL. Ministério do Meio Ambiente. Programa Município Educadores Sustentáveis. Ed.2. Programa Nacional de Educação Ambiental. Brasília: Ministério do Meio Ambiente, 2005.

CARVALHO, I.C.M. Educação Ambiental Crítica: nomes e endereçamentos da educação. In: LAYRARGUES, P.P. (org.). Identidade da educação ambiental brasileira. Ministério do Meio Ambiente. Brasília. p.13-24, 2004. Disponível em: $<$ http://www.mma.gov.br/estruturas/educamb/ arquivos/livro ieab.pdf>. Acesso em: 13 Jul 2017.

CASTELA, P.R.; BRITEZ, R.M. 2004. A Floresta com Araucária no Paraná: conservação e diagnóstico dos remanescentes florestais. Brasília, Fundação de Pesquisas Florestais do Paraná. 236p.

GUIMARÃES, S.T.L. Reflexões a respeito da paisagem vivida, topofilia e topofobia à luz dos estudos sobre experiência, percepção e interpretação ambiental. Geosul, v.17, n.33, 2002. Disponível em: $<$ https://periodicos.ufsc.br/index.php/geosul/article/view/13971>. Acesso em: 13 Jul 2017.

HAESBAERT, R. O mito da desterritorialização: do "fim dos territórios" à multiterritorialidade. Rio de Janeiro: Bertrand Brasil, 2004.

HAUER, M. Conflitos e tensões no uso da terra: agricultura familiar e legislação ambiental no Paraná. Tese de doutoramento apresentada ao Programa de Pós-Graduação em Engenharia Florestal da Universidade Federal do Paraná, 240p. $2010 . \quad$ Disponível em: $<$ http://www.floresta.ufpr.br/defesas/pdf dr/2009/t270 0309-D.pdf>. Acesso em: 15 Maio 2017.

JACOBI, P.R. Educação ambiental, cidadania e sustentabilidade. Cadernos de Pesquisa. São Paulo: Autores Associados, n. 118, p.189-205, 2003. Disponível em: <http://atividadeparaeducacaoespecial.com/wp-content/uploads/2014/09/ cidadaniaesustobriga.pdf>. Acesso em: 11 Jul 2017.

JACOBI, P.R. Educação ambiental: o desafio da construção de um pensamento crítico, complexo e reflexivo. Educação e Pesquisa, v.31, n.2, p.233-50, 2005.2 Disponível em: <http://www.scielo.br/pdf/ep/v31n2/a07v31n2.pdf>. Acesso em: 11 Jul 2017.

KAWAHARA, L.S.I.; SATO, M.T. Festa de São Pedro e serviços ecossistêmicos culturais: aprendizagens de um grupo pesquisador em educação ambiental no pantanal. Revbea, São Paulo, v.10, n.1, p.221-240, 2015. 
LAGES, V.; BRAGA, C.; MORELLI, G. (orgs.). Territórios em movimento: cultura e identidade como estratégia de inserção competitiva. Rio de Janeiro: Relume Dumará / Brasília, SEBRAE, 352p., 2004. Disponível em: $<$ http://inspirebr.com.br/uploads/midiateca/d64c55dfd943251ede2b6330035a59 94.pdf\#page=24>. Acesso em: $10 \mathrm{Jul} 2017$.

LITTLE, P.E. Territórios sociais e povos tradicionais no Brasil: por uma antropologia da territorialidade. Série Antropologia. Brasília: DAN/UnB. N.322, p.251-289, 2002. Disponível em: <http://www.dan.unb.br/images/pdf/ anuario antropologico/Separatas\%202002-2003/2002-2003 paullittle.pdf>.

Acesso em: 11 Jul 2017.

LOBINO, M.G.F. A práxis ambiental educativa: diálogo entre diferentes saberes. 2. ed., Vitória: EDUFES, 2013. 258 p. Disponível em: $<$ http://repositorio.ufes.br/bitstream/10/829/1/livro\%20edufes\%20Pr\%C3\%A1xis \%20ambiental\%20educativa\%20di\%C3\%A1logo\%20entre\%20diferentes\%20sa beres.pdf>. Acesso em: 10 Out 2017.

LOUREIRO, C.F.B. Premissas teóricas para uma educação ambiental transformadora. Ambiente e Educação, Rio Grande, v8, p.37-54, 2003. Disponível em: <https://www.seer.furg.br/ambeduc/article/view/897>. Acesso em: 11 Out 2017.

LOUREIRO, C.F.B. Educação ambiental e gestão participativa na explicitação e resolução de conflitos. Gestão em Ação. UFBA. v.7, n.1, p.237-253, 2008. Disponível em: <http://www.gestaoemacao.ufba.br/revistas/gav7n104. PDF\#page $=37>$. Acesso em: 12 Jul 2017.

NETO, A.C.; SILVA, T.C. Projeto Político-Pedagógico como mecanismo de autonomia escolar. Gestão em Ação. UFBA. v.7, n.1, p.7-24, 2004. Disponível em: $\quad<$ http://www.gestaoemacao.ufba.br/revistas/gav7n104.PDF\#page=37>. Acesso em: 12 Jul 2017.

RISSO, L.C. Os conceitos de percepção e território como lentes para o entendimento cultural. Terr@Plural, v.8, n.2, p.309-319, 2014. Disponível em: $<$ http://www.revistas2.uepg.br/index.php/tp/article/view/6438>. Acesso em: 09 Out 2017.

SANTOS, M. O retorno do território. OSAL: Observatório Social de América Latina, ano 6. n. 16, p. 251-261, 2005. Disponível em: <http://bibliotecavirtual.clacso.org.ar/ar/libros/osal/osal16/D16Santos.pdf>.

Acesso em: 09 Out 2017.

SANTOS, J.E; et al. O cenário da pesquisa no dialogo EcológicoEducativo. São Carlos: Rima, 2009.

SATO, M.; SANTOS, J.E. Tendências nas pesquisas em educação ambiental. Santa Cruz do Sul. In: NOAL, F.; BARCELOS, V. (Orgs.) Educação ambiental e cidadania: cenários brasileiros. Santa Cruz do Sul: EDUNISC, p. 253-283, 2003. Disponível em: <https://professormassena.files.wordpress.com/2011/09/ pesquisas-em-ea.pdf $>$. Acesso em: 14 Out 2017. 
SAUVÉ, L. Uma cartografia das correntes em educação ambiental. In: SATO, M., CARVALHO, I. (Orgs.). Educação Ambiental: pesquisa e desafios. Porto Alegre: Artmed. p. 17-44. 2005. Disponível em: $<$ http://web.unifoa.edu.br/portal ensino/mestrado/mecsma/arquivos/sauvel.pdf>. Acesso em: 10 Jul 2017.

TEIXEIRA, C.; OLIVEIRA, M.E. A temática ambiental na educação: o conhecimento em construção. Anais do IV Encontro Nacional da ANPPAS (Associação Nacional de Pós-Graduação em Ambiente Sociedade), 200 Brasília. $2008 . \quad$ Disponível em: $<$ http://www.anppas.org.br/encontro4/cd/ARQUIVOS/GT9-810-49520080510233917.pdf $>$. Acesso em 11 Out 2017. 